\title{
Therapeutic hypothermia in Post - cardiac arrest : It is time to revisit the guidelines.
}

\author{
Afroz Shirin ${ }^{1}$, Tasbirul Islam² \\ Division of Pulmonary \& Critical Care Medicine, Indiana University Health Arnett Hospital, Lafayette, IN, USA
}

\begin{abstract}
:
Background: Targeted Temperature Management (TTM), previously known as therapeutic hypothermia is an important tool for prevention and reversal of neurological injury and mortality reduction. Over the recent period, the use of induced hypothermia has raised many questions and recent large, randomized controlled trials (RCTS) have failed to demonstrate the benefit of TTM on clinical outcomes. The objective of this article was to compare different studies on neurological outcomes after use of TTM in different clinical situations, different temperatures and rates of cooling.

Methods: We incorporated studies from 1950s to recent years using search engines like PubMed, Science Direct, Google Scholar.

Results: Initial two small, unblinded trials have demonstrated improved neurological outcome in out of hospital shockable cardiac arrest. Recent studies showed that TTM was not associated with higher rates of survival or favorable neurological outcome in patients with IHCA and was rather associated with potential harm, lower likelihood of survival after discharge and long term neurological survival. TTM also didn't show any favorable results in non-shockable cardiac arrests. Hypothermia of $36^{\circ} \mathrm{C}$ did not confer much benefit over $32^{\circ} \mathrm{C}-34^{\circ} \mathrm{C}$.

Conclusion: Recent large studies didn't show no strong evidence that TTM is highly effective. Further methodologically robust studies are required in both shockable and non-shockable cardiac arrest for TTM to have any effect on neurological outcome.
\end{abstract}

\section{Introduction:}

Mild therapeutic hypothermia, now known as Targeted Temperature Management (TTM), has been proposed for patients resuscitated after cardiac arrest by American Heart Association (AHA) in 2005 to improve rates of long-term neurologically intact survival. Cardiac arrest, both in and out of hospital, occurs commonly and results in high mortality and neurologic morbidity. This article will provide a focused update on the advances in the care of post cardiac arrest patients, highlighting the benefits, controversies and adverse effects of therapeutic hypothermia as a treatment for global ischemic brain injury.

\section{What is Targeted Temperature Management?}

Targeted temperature management refers to deliberate reduction of the core body temperature, typically to a range of about $32^{\circ}$ to $34^{\circ} \mathrm{C}\left(89.6^{\circ}\right.$ to $\left.93.2^{\circ} \mathrm{F}\right)$ in patients who don't regain consciousness after return of spontaneous circulation following a cardiac arrest.

\footnotetext{
1. Afroz Shirin MD, Clinical Observer

2. Tasbirul Islam MD, FCCP, MRCP (UK), Clinical Associate Professor, Indiana University
}

Corresponding Author:

Tasbirul Islam

MD, FCCP, MRCP (UK)

Division of Pulmonary \& Critical Care Medicine

Indiana University Health Arnett Hospital

Lafayette, IN, USA

E-mail : tislam@iuhealth.org;tasbirul@msn.com
Ischemia-Reperfusion Brain Injury---Neuroprotective mechanism of hypothermia:

Circulatory collapse following cardiac arrest initiate anaerobic metabolism which disrupts adenosine triphosphate-dependent cellular pumps, resulting in excessive calcium and glutamate excretion. This excess makes brain cells more excitable, causing worsening hypoxemia leading to mitochondrial and cellular death. Cellular death along with disrupted the blood-brain barrier results in cerebral edema, producing further damage.

Even though the mechanism underlying the neuroprotective effect of hypothermia is not fully understood the recent randomized trials demonstrate that therapeutic hypothermia is associated with improved survival and functional outcome and has numerous hypotheses. Hypothermia reduces the cerebral metabolic rate for oxygen (CMRO2) by $6 \%$ for every $1^{\circ} \mathrm{C}$ reduction in brain temperature $>28^{\circ} \mathrm{C}$ in a normal brain. The ability of hypothermia to affect multiple points of the injury cascade may contribute significantly to its success as an intervention. These effects include retarding the initial rate of ATP depletion ${ }^{15,16}$, reducing intracellular calcium, which can in turn lead to mitochondrial damage, free radical injury and apoptosis (programmed cell death) $)^{17-18}$, reducing excitotoxic neurotransmitter release ${ }^{20}$, altering intracellular messenger activity ${ }^{21}$, reducing inflammatory responses ${ }^{22}$, altering gene expression and protein synthesis ${ }^{23,24}$, changing glutamate receptor regulation ${ }^{25}$ and limiting the breakdown of the blood-brain barrier ${ }^{26}$, neuronal apoptosis, and death ${ }^{1}$. 


\section{Duration and methods of cooling:}

Cooling should be initiated as soon as possible after ROSC but appears to be successful even if delayed (e.g. 4 to 6 hours). The European study suggests that the sooner cooling is initiated after reperfusion from cardiac arrest, the better the outcome. Attainment of a core temperature of $32^{\circ} \mathrm{C}$ to $34^{\circ} \mathrm{C}$ had an interquartile range of 4 to 16 hours $^{5}$. Three phases of TTM include induction, maintenance, and rewarming. Normothermia should be restored only slowly as rebound hyperthermia is common and should be avoided. Rewarming can be begun 24 hours after the time of initiation of cooling, with avoidance of hyperthermia ${ }^{10}$. One can obtain 2 cooling blankets and cables (one machine) to "sandwich" the patient; each blanket should have a sheet covering it to protect the patient's skin. Cooling techniques also include packing the patient in ice (groin, chest, axillae, and sides of neck); use of wet towels, cooling helmet and fanning the patient to bring to a temperature between $32^{\circ} \mathrm{C}$ and $36^{\circ} \mathrm{C}^{11}$; with avoidance of packing ice on top of the chest, which may impair chest wall motion. In a recent study, intravenous infusion of $30 \mathrm{~mL} \cdot \mathrm{kg}-$ 1 of crystalloid at $4^{\circ} \mathrm{C}$ over 30 minutes reduced core temperature significantly and did not cause pulmonary edema $^{12}$. The incidence of complications is likely to increase if the core temperature falls considerably below $32^{\circ} \mathrm{C}$. Rewarming should be undertaken slowly to avoid worsening neurologic injury, sudden vasodilatation, and shock $^{13,14}$. So careful monitoring of temperature with sedation is important during use of therapeutic hypothermia.

\section{Clinical trials favoring TTM:}

For decades therapeutic hypothermia had been advocated as a treatment to improve neurologic outcome in hypoxic brain injury after cardiac arrest. In the late 1950 s successful use of moderate hypothermia $\left(28^{\circ} \mathrm{C}\right.$ to $\left.32^{\circ} \mathrm{C}\right)$ to protect the brain against the global ischemia during some open-heart surgeries and post cardiac arrest were described ${ }^{2-4}$. But the early studies showed that moderate hypothermia was associated with many complications and was not clearly beneficial. In 2002 two prospective, multi-centered, randomized, controlled trials with mild hypothermia with target temperatures of $32^{\circ} \mathrm{C}$ $-34^{\circ} \mathrm{C}$ applied to comatose survivors after cardiac arrest compared with a normothermic control group have demonstrated improved neurologic outcome in Europe ${ }^{5}$ and in Australia $^{6}$. In the Australian study (n 77), 21 of 43 patients (49\%) of VF related cardiac arrest treated with hypothermia had good neurological function at discharge (to home or a rehabilitation facility) compared with 9 of $34(26 \%)$ in the normothermia group (RR $1.85,95 \%$ CI 0.97 to 3.49 , NNT=4). Mortality at discharge was 22 of $43(51 \%)$ in the hypothermia group and 23 of $34(68 \%)$ in the normothermia group (RR $0.76,95 \%$ CI 0.52 to $1.10, \mathrm{NNT}=6)^{6}$. In European study 273 patients with out-of-hospital cardiac arrest due to shockable rhythms (ventricular fibrillation or ventricular tachycardia) at 9 European centers, hypothermia (32-34 $)$ led to improved survival ( $59 \%$ at 6 months vs. $45 \%$ with usual care) and better neurologic outcome (55\% vs 39\% achieving CPC 1-2) ${ }^{5}$. Both studies included only patients with ventricular tachycardia and ventricular fibrillation.
In October 2005, as a result of these two small studies, the Advanced Life Support (ALS) Task Force of the International Liaison Committee on Resuscitation (ILCOR) made the following recommendations: unconscious adult patients with spontaneous circulation after out-of-hospital cardiac arrest should be cooled to $32^{\circ} \mathrm{C}$ to $34^{\circ} \mathrm{C}$ for 12 to 24 hours when the initial rhythm was ventricular fibrillation (VF). Such cooling may also be beneficial for other rhythms or in-hospital cardiac $\operatorname{arrest}^{7,8}$ even though there were not many studies to prove that. On the other hand, some randomized control trials also suggested no significant benefit in neurologic outcome and survival at 6 months in $\mathrm{OHCA}$ for $33^{\circ} \mathrm{C}$ and $36^{\circ} \mathrm{C}^{9}$.

\section{Hypothermia - is it ineffective or harmful?}

So far, all the early studies mentioned were of small, unblinded and some were just observational studies, conceivably not taking all the factors in consideration, created or inflated by the lack of blinding to treatment allocation with its possible biases, or simply teams being over excited for a possibility of new beneficial treatment and proving its potential. In recent times the largest international, multicentered, randomized trial yet, Niklas Nielsen et al. ${ }^{27}$ probe further, examining whether TTM is effective in patients with (VT/VF) and without shockable rhythms (PEA /asystole), hypothermia at a targeted temperature of $33^{\circ} \mathrm{C}$ in unconscious survivors of out-of-hospital cardiac arrest of presumed cardiac cause did not confer a benefit as compared with a targeted temperature of $36^{\circ} \mathrm{C}$.

In RINSE trial ${ }^{34}$ authors randomized $\sim 1200$ patients with out of hospital cardiac arrest in Australia to either therapeutic hypothermia initiated pre-hospital with 2 liters of $3^{\circ} \mathrm{C}$ saline infusion or usual prehospital care. All patients were then transported to cardiac care centers where therapeutic hypothermia was performed as standard post-arrest care. Temperature targets at the cardiac centers changed during the trial, with many centers switching from a $36^{\circ}$ to a $33^{\circ}$ target based on the TTM study. Patients with shockable rhythms receiving the cold saline did worse immediately, with $41 \%$ achieving return of spontaneous circulation, vs. $50 \%$ achieving ROSC who did not receive cold saline. But the standard care patients caught up, unfortunately: equivalent proportions of patients survived to hospital discharge (a dismal $10 \%$ vs $11 \%$ ).It was hypothesized that the extra fluid bolus in patients with cardiac failure may have resulted in the initial deaths after unsuccessful CPR.

Hassimi Edris et al. and Kim $\mathrm{F}$ et al. ${ }^{28}$ conducted a large OHCA survivors cohort study highlighting the independent association between TTM and better improved neurological outcome at discharge in shockable (VT/VF) patients at hospital discharge. In contrast, TTM was not associated with good outcome in non-shockable (PEA/Asystole) patients. Further investigations are needed to clarify this lack of efficiency in PEA/asystole where induced hypothermia was related to a trend toward a rather harmful effect. Not only that, a study in a large national registry shows that treatment with TTM was not associated with higher rates of survival at discharge or favorable neurological survival in patients with 
In-Hospital Cardiac Arrest (IHCA) and was rather associated with potential harm and with a lower likelihood of survival to hospital discharge and a lower likelihood of favorable neurological survival in one year observation ${ }^{28}$. Because the In-Hospital Cardiac Arrests differ markedly in response times, comorbidity burden, and cardiac arrest etiology from the out-of-hospital setting. These observational findings warrant a large randomized clinical trial to assess efficacy of TTM for in-hospital cardiac arrest. Many argues that the absence of benefits seen in these cases was not because deep hypothermia is not helpful - rather it was because the patients weren't cooled quickly enough during CPR or in the time of intra-cardiac arrest. Additional studies of intra-arrest cooling are needed to investigate alternate techniques other than bolus cold saline for induction of therapeutic hypothermia during $\mathrm{CPR}^{29}$.

Dumas et al prospectively observed 1145 consecutive victims of out-of-hospital cardiac arrest who survived to admission in France between 2000 and 2009. Among VT/VF patients, 65\% got therapeutic hypothermia, while $60 \%$ of PEA/asystole patients did, with higher proportions receiving hypothermia later in the study period ( 86 and $73 \%$ respectively). Most people in the PEA/asystole cohort had asystole (80\%). Therapeutic hypothermia was strongly associated with improved neurologic outcome in VT/VF (44\% in those cooled vs. $29 \%$ in those not, $\mathrm{p}<0.001)$, but seemed to make no difference in PEA/asystole (15 vs $17 \%)^{35}$.

Besides these TTM can also produce potential adverse effects, including arrhythmias by slowed cardiac conduction, hyperglycemia due to insulin resistance needing more insulin dose ${ }^{30}$, coagulopathy by slow platelet function leading to hemorrhage ${ }^{31}$, infection by impaired leucocyte function ${ }^{32}$. Hypothermia induced 'Cold diuresis' leads to hypovolemia, hypokalemia, hypomagnesemia and hypophosphatemia ${ }^{33}$. Until further data are available, therapeutic hypothermia should not be used for patients with severe cardiogenic shock or life-threatening arrhythmias, pregnant patients, or patients with primary coagulopathy.

\section{Conclusion:}

American Heart Association Guidelines for targeted temperature management following cardiac arrest based on two small, unblinded studies which was shockable rhythms out of hospital cardiac arrest. More recent larger studies including non-shockable rhythms in hospital cardiac arrest have not shown enough benefits rather few studies showed worse outcomes who got hypothermia. Patients experiencing cardiac arrest in the hospital are a very different population than those experiencing arrest outside the hospital, they're sicker and receive resuscitation including defibrillation much earlier. In trials that have studied the effect of varying temperature, TTM with targeted temperature of $33^{\circ} \mathrm{C}$ compared with $36^{\circ} \mathrm{C}$ in unconscious survivors of out-of-hospital cardiac arrest has not shown much promise, in some cases worsening the prognosis. In addition, rapid cooling versus slow cooling is another burning question. So the important questions that need to be answered definitively are, "when, how and how much? We need larger series of standardized, randomized, double blinded clinical trials in different clinical, in and out of hospital setting with alternate cooling techniques and registry-reported data to answer all these questions.

\section{References:}

1. Negovsky VA. Postresuscitation disease. Crit Care Med. 1988 Oct. 16 (10):942-6.

2. Benson DW, Williams GR, Spencer FC. The use of hypothermia after cardiac arrest. Anesth Analg. 1959; 38: 423-428.

3. Williams GR, Spencer FC. The clinical use of hypothermia following cardiac arrest. Ann Surg. 1958; 148: 462-468.

4. Ravitch MM, Lane RR, Safar P. Lightning strike: report of a case with recovery after cardiac massage and prolonged artificial respiration. N Engl J Med. 1961; 264: 36-38.

5. The Hypothermia after Cardiac Arrest Study Group. Mild therapeutic hypothermia to improve the neurologic outcome after cardiac arrest. N Engl J Med. 2002; 346: 549-556.

6. Bernard SA, Gray TW, Buist MD. Treatment of comatose survivors of out-of-hospital cardiac arrest with induced hypothermia. N Engl J Med. 2002; 346: 557-563.

7. Emergency Cardiovascular Care (ECC) Committee. 2005 American Heart Association Guidelines for Cardiopulmonary Resuscitation and Emergency Cardiovascular Care. Circulation. 2005;112: IV1-203.

8. [Guideline] Callaway CW, Donnino MW, Fink EL. Part 8: Post-cardiac arrest care: 2015 American Heart Association guidelines update for cardiopulmonary resuscitation and emergency cardiovascular care. Circulation. 2015 Nov 3. 132(18 suppl 2):S465-82.

9. Nielsen $\mathrm{N}$, Wetterslev J, Cronberg T. Targeted temperature management at $33^{\circ} \mathrm{C}$ versus $36^{\circ} \mathrm{C}$ after cardiac arrest. N Engl J Med. 2013 Dec 5. 369(23):2197-206.

10. Callaway CW, Donnino MW, Fink EL. Part 8: Post-cardiac arrest care: 2015 American Heart Association guidelines update for cardiopulmonary resuscitation and emergency cardiovascular care. Circulation. 2015 Nov 3. 132(18 suppl 2):S465-82.

11. Wright WL, Geocadin RG. Postresuscitative intensive care: neuroprotective strategies after cardiac arrest. Semin Neurol. 2006 Sep. 26(4):396-402.

12. Bernard S, Buist M, Monteiro O. Induced hypothermia using large volume, ice-cold intravenous fluid in comatose survivors of out-of-hospital cardiac arrest: a preliminary report. Resuscitation. 2003; 56: 9-13.

13. Schwab S, Schwarz S, Spranger M. Moderate hypothermia in the treatment of patients with severe middle cerebral artery infarction. Stroke. 1998;29:2461-6.

14. Felberg RA, Krieger DW, Chuang R. Hypothermia after cardiac arrest: feasibility and safety of an external cooling protocol. Circulation. 2001;104:1799-804.

15. Kramer RS, Sanders AP, Lesage AM. The effect of profound hypothermia on preservation of cerebral ATP content during circulatory arrest. J Thorac Cardiovasc Surg. 1968;56:699-709.

16. Welsh FA, Sims RE, Harris VA. Mild hypothermia prevents ischemic injury in gerbil hippocampus. J Cereb Blood Flow Metab. 1990;10:557-63.

17. Colbourne F, Sutherland G, Corbett D. Postischemic hypothermia: a critical appraisal with implications for clinical treatment. Mol Neurobiol. 1997; 14: 171-201. 
18. Ginsberg MD, Sternau LL, Globus MY. Therapeutic modulation of brain temperature: relevance to ischemic brain injury. Cerebrovasc Brain Metab Rev. 1992; 4: 189-225.

19. Safar PJ, Kochanek PM. Therapeutic hypothermia after cardiac arrest. N Engl J Med. 2002; 346: 612-613.

20. Busto R, Globus MY, Dietrich WD. Effect of mild hypothermia on ischemia-induced release of neurotransmitters and free fatty acids in rat brain. Stroke. 1989;20:904-10.

21. Cardell M, Boris-Moller F, Wieloch T. Hypothermia prevents the ischemia-induced translocation and inhibition of protein kinaseCin the rat striatum. J Neurochem. 1991;57:1814-7.

22. Toyoda T, Suzuki S, Kassell NF. Intraischemic hypothermia attenuates neutrophil infiltration in the rat neocortex after focal ischemia-reperfusion injury. Neurosurgery. 1996;39:1200-5.

23. Kumar K, Wu X, Evans AT. The effect of hypothermia on induction of heat shock protein (HSP)-72 in ischemic brain. Metab Brain Dis. 1995;10:283-91.

24. Kumar K, Wu X, Evans AT. Expression of c-fos and fos-B proteins following transient forebrain ischemia: effect of hypothermia. Brain Res Mol Brain Res. 1996;42:337-43.

25. Colbourne F, Grooms SY, Zukin RS. Hypothermia rescues hippocampal CA1 neurons and attenuates down-regulation of the AMPAreceptor GluR2 subunit after fore-brain ischemia. Proc Natl Acad Sci U S A. 2003;100:2906-10.

26. Dempsey RJ, Combs DJ, Maley ME. Moderate hypothermia reduces postischemic edema development and leukotriene production. Neurosurgery. 1987;21:177-81.

27. Nielsen N, Wetterslev J, Cronberg T, Erlinge D, Gasche Y,et al. Targeted Temperature Management at $33^{\circ} \mathrm{C}$ versus $36^{\circ} \mathrm{C}$ after Cardiac Arrest. N Engl J Med November 17, 2013. DOI: 10.1056/NEJMoa1310519.
28. Hachimi-Idrissi S, Corne L, Ebinger G, Michotte Y, Huyghens L. Mild hypothermia induced by a helmet device: a clinical feasibility study. Resuscitation. 2001;51:275-281.

29. Kim F, Olsufka M, Longstreth WT Jr., Maynard C, Carlbom D, Deem S, et al. Pilot randomized clinical trial of prehospital induction of mild hypothermia in out-of-hospital cardiac arrest patients with a rapid infusion of 4 degrees c normal saline. Circulation. 2007;115:3064-3070

30. Polderman KH, Herold I. Therapeutic hypothermia and controlled normothermia in the intensive care unit: practical considerations, side effects, and cooling methods. Crit Care Med 2009; 37:1101.

31. Reed RL 2nd, Bracey AW Jr, Hudson JD. Hypothermia and blood coagulation: dissociation between enzyme activity and clotting factor levels. Circ Shock 1990; 32:141.

32. Perbet S, Mongardon N, Dumas F. Early-onset pneumonia after cardiac arrest: characteristics, risk factors and influence on prognosis. Am J Respir Crit Care Med 2011; 184:1048.

33. Polderman KH, Peerdeman SM, Girbes AR. Hypophosphatemia and hypomagnesemia induced by cooling in patients with severe head injury. J Neurosurg 2001; 94:697.

34. Bernard SA, Smith K. Induction of therapeutic hypothermia during out of hospital cardiac arrest using a rapid infusion of cold saline: The RINSE trial (Rapid Infusion of Cold Normal Saline). Circulation 2016 Sept 13; 134 (11) 797-805.

35. Florence Dumas, David Grimaldi. Is hypothermia after cardiac arrest effective in both shockable and non shockable patients? Circulation 2011;123: 877-886, 